\title{
Social Dimensions and Participation in Vocational Education and Training: An Introduction in the Special Issue
}

\author{
Franz Kaiser* and Susann Krugmann \\ University of Rostock, Institute for Vocational Education, \\ August-Bebel-Str. 28, 18055 Rostock, Germany
}

Published: 22.11 .2018

\section{Introduction}

After the first "Crossing Boundaries in Vocational Education and Training - Conference" took place in Bremen in 2015, organized by the ITB, the conference focusing on the social dimension and participation was continued in Rostock in August 2017 at the ibp in collaboration of Michael Gessler, Larissa Freund (ITB Bremen) and Franz Kaiser, Susann Krugmann (ibp Rostock). The thematic focus on the social dimension and participation takes place in many areas of life and is of decisive importance for decisionmaking and decision-making processes. Particularly in times of structural change and the associated transition to a service and knowledge society, it is evident that operational structures are changing and being reorganised. The internationalisation of the economy is also progressing in this way, leading to increasing demands on the level of qualifications (Wilkens \& Leber, 2003). It is precisely because of this development that the sociology of work and industry demands more or less immanent participation (Brater, 2010). So that the question of why should not actually arise if we assume that employees should develop further. In general, participation is a key subject of democratic societies, understood as a multi-layered, interlocked and highly dynamic process and less as an achieved, fixed state. In this context, changed focal points are relevant for the different areas of society, since these take into account both individual and collective or institutional activities of subjects or cooperation between groups of persons or institutions. The predominance of a relationship of trust and reliability within society is fundamental. Only if the different actors can create an encouraging climate of mutual trust will it be easier to develop a

*Corresponding author: Franz.kaiser@uni-rostock.de

ISSN: 2197-8646

http://www.ijrvet.net 
social and participatory attitude towards the new and the foreign. Participation thus requires a high degree of initiative, courage, openness, willingness to take risks and creative commitment, and opens our eyes to the challenges of social dimensions in the vocational training context.

This approach is in the tradition of educational enlightenment, combined with Immanuel Kant's request "Have the courage to use your own intellect" and the critical thinking of the Frankfurt School, in search of the expansion of individual possibilities for the development of one's own life under contradictory circumstances. The individual should be encouraged to develop himself and for society. The focus is on various questions. How can vocational training benefit individual learners and their interests and at the same time meet the requirements of a division of labour economy with an interest in special competences? How can vocational training enable trainees to analyse the structure of vocational training and their professional future? How can they be encouraged to deal with the contradictions and develop innovative design possibilities in their workplaces with their colleagues and managers? What is necessary in the design of VET systems to integrate different learners and provide them with ways to achieve their aims? What does this mean for VET research?

For this reason, we have invited scientists from different countries and various fields of vocational education and training and related disciplines to participate in the conference and give lectures on the following reference levels.

Boundaries defining and shaping the field of initial and continuing vocational education and training:

\section{Systems}

Socio-culturally different vocational training systems have developed conceptually. The comparison of different qualification systems and the management of vocational training systems are of theoretical and practical importance in the context of economic development and international cooperation. The comparison enables the identification of strengths and need for improvement and the identification of gaps. In a comparative perspective with regard to the current situation and the necessary/possible development directions of the respective systems, the question arises of promoting educational justice and a successful transition to the labour market.

\section{Institution and Agency}

The various vocational training systems are defined by the interaction of the involved institutions, stakeholders and participating individuals. These are not only an expression of professionalization, but also show the system boundaries and interfaces. These inter-institutional spaces of open or closed discourses, depend on the regional and national culture and the political models of the cooperation partners. Which rules have been established? How do educational institutions and labour institutions communicate and interact? Which cooperations and transitions are possible or necessary to increase participation? 


\section{Practice and Actor}

Practices have been established in the institutions or regulations to deal with the central issues of teaching, learning and competence development. Teaching and learning practices can help to lower the boundaries of qualifications and employment biographies. What does it take for teacher training, student collaboration and research itself to cross institutional boundaries or focus on central conflicts and contradictions to encourage individuals to face them? How can the goal of education in vocational education and training didactics and the culture of interaction be ensured? What are the different formal and informal practices, how do they relate to each other and what developments are discernible for social inclusion and the public welfare?

The three reference levels were influenced by conceptual ideas, terms and constructs. In 2017 we focused on conceptual ideas and structural approaches that help to cross the borders of democratic society with well-trained and self-confident employees and sustainable development. Therefore it was discussed which developments have emerged and which of them are suitable for future requirements and the specific history of their region?

In order to provide the conference with a corresponding framework, we have invited representatives keynote speakers from various research areas to address these questions as part of their work. As keynotes we could win Stephanie Matselang Allais (South Africa), Sabine Pfeiffer (Germany), Markus Neuenschwander (Switzerland) and James Avis (United Kingdom).

This Special Issue of the Crossing Boundaries Conference focuses on the social and participatory dimensions of vocational education and training. Stephanie Matselang's critical contribution about the labour market outcomes of National Qualification frameworks has already been published in another journal and is therefore not included in the Special Issue. A short version is included in the proceedings of the conference (Kaiser \& Krugmann 2017). She stated the absent of empirical evidence of benefit of NQFs to the labour market, the employers and employees based on her, six countries including study 1

James Avis' contribution entitled Crossing Boundaries: VET, the Labour Market and Social Justice fundamentally analyses the connection between vocational education and training, the labour market and social justice against the background of criticism of capitalism and changes on the labour market.

The orientation of vocational education and training towards the management of work processes is linked to the competence discourse, which provides for different narrow or broad qualification profiles. The design of the associated educational pathways and qualification structures is a continuous political process of negotiation in the tension between capital and labour. Recently, neoliberal tendencies have taken place in both Sweden and Germany, which have made new low-wage sectors and labour intensification possible, for example. Vocational training is described by Avis as "contested terrain".

\footnotetext{
${ }^{1}$ All contributions of the keynote speakers are also in the $2{ }^{\text {nd }}$ proceeding of the Crossing Boundaries: Social Dimension and Participation. The only exception is the keynote by Prof. Markus Neuenschwander.
} 
He is focussing England's situation about qualification with a simultaneous skills gap. The neoliberalist thinking that strengthened in England associated with Margaret Thatcher has spread to continental Europe and has nested in common sense. It leads to acceptance of social and regional inequality. The effects of digitisation and the global networking of work also vary from region to region and are currently affecting university graduates and knowledge work in particular. At the same time, studies of wage developments for work always ignore unpaid work. The problem is that by linking vocational training and the labour market, the development of qualifications for this socially valuable work remains outside the field of vision. Avis fears that the increasingly liberated international market movements will have devastating consequences for the employment and integration services of the economy, which cannot be countered with reformism to harmonize life chances under the illusion of meritocracy. In contrast, he emphasizes a Marxist position aimed at a post-capitalist society.

If vocational education and training is to develop more strongly into democratic and humanistic education, this will not only start with the content, but also with the form in which trainees are taught in vocational schools. This is the starting point in Franz Kaiser's article entitled "Theme Centered Interaction in Critical Vocational teacher education", which calls for a stronger focus on the qualification of prospective teachers at vocational schools.

Starting from the changed requirements in the working world and a shift from acting according to instructions to acting independently and the increase of individual responsibility in the working world, he clarifies the contradictions in vocational education and training by claiming the critical theory of the Frankfurt School and its goals for vocational education and training.

The humanisation of the working world, which has taken place in Germany since the 1970s, also requires a change in vocational training in which social skills are also developed as the ability to resist. He sees the theme-centred interaction as a starting point for this, making it easier for future vocational school teachers to focus their teaching more on the independent development of their students. The reflection of one's own biography and the unconscious adoption of values and behaviour associated with the path of life should thus be made more accessible to one's own reflection. In communication situations that permit and promote authentic encounters and interactions, this can be learned during the course of study and can thus contribute to an emancipative vocational training.

The article thus clarifies the question of the practical development of participation through the implementation of a method that teaches participative and creative teaching design and is at the same time founded in values that give the individual opportunities for growth and at the same time take into account the interests of all and nature.

In contrast, Sabine Pfeiffer's contribution looks at the activities of employees in highly automated and digitized work environments and discusses the potential of automation through new technology (industry 4.0) in manufacturing and the automotive industry. She shows in her article The future of employment on the shop floor: Why production jobs are less susceptible to computerization than assumed the differences between routine work and non-routine work through qualitative research and focuses on the relevance of 
non-routine work especially in highly automated and digitized work environments.

Previous research shows two decisive effects in this context when a highly automated and/or digitized work environment is created: Substitution effects (routine tasks are automated) and complementarity effects (support for non-routine tasks). Pfeiffer criticizes that these categories are used to estimate the replacement of human work and to give a probability prognosis of the replacement. Her study focuses on the relationship between the subjectivation of work performance and the ability to survive. She combines the concept of subjectifying work action and the concept of living labouring capacity and assumes that a combination of qualitative diagnoses of human-machine interaction with quantitative labour market data provides insights into probable future developments in work organization. The aim is to improve methods for investigating relevant developments and to create a basis for continuous and early reporting on changes in companies and workplaces. At the end, she develops an index (LC index) that collects "living capacity for work" rather than routine work.

The contribution by Markus Neuenschwander, Jan Hofmann, Andreas Jüttler and Stephan Schumann focuses on the career aspirations and career choices of students at secondary school in Switzerland. The article Professional Desires and Career Decisions: Effects of Professional Interests, Role Models, and Internship in Lower Secondary School focuses on the effects of vocational interests, exemplary occupations and the internships completed with regard to the implementation of the career choice. In order to be able to present the effects, a standardised questionnaire was developed and used in grade 7 and grade 9 (longitudinal study).

Based on the career decision model, the authors assume that the career decision of pupils results from the vocational goals that correspond to the vocational interests. In addition, the decision is centrally influenced by reference persons (e.g. role models such as parents, relatives, friends and others). So that pupils only indirectly have professional experience of their role models. The aim is to determine the extent to which the desired vocational environment is realised in the chosen training and how these findings can be predicted. It is assumed that career aspirations are more likely to be realised in the same environment if the first internship completed has a positive connotation. If the internship is assessed as negative by the students and they also receive negative feedback, they explore other professional environments that fit their interests and competences.

The study shows that there is a significant correspondence between the professional environment of the role models and the desired and selected training occupation of the pupils. This also applies to the relationship between the professional environment of the traineeship and the desired and chosen training occupation. With its results, the study emphasises that both direct and indirect experiences of the pupils flow into the career aspirations and career decisions. Thus it could be proven that the social-cognitive career theory of Lent et al. (1994) is suitable to explain the influence of the role models and to make a prediction on the pupils' occupational environment that has so far only been theoretically assumed.

What links the four contributions together is their critical and conceptual view on different fields and reference levels of vocational education. There is the level of political discourse and shaping structure (Stephanie Allais-Matseleng, James Avis) where VET 
research can offer a critical reflection towards aims and evidence. On the level of practice research we can analyse career decisions (Neuenschwander et.al.) and how to encourage VET teachers to create participative lectures and social inclusion at VET schools (Kaiser). And at the same level the insight in Work 4.0 and the possibilities to strength living capacity for work (Pfeiffer).

We like to thank all the 100 participants at the conference in Rostock, the contributors from different countries and cultures, the support of our colleagues from Bremen and at the Institute for Vocational education in Rostock and especially the authors in this special issue for their patience and collaboration.

\section{References}

Kaiser, F., \& Krugmann, S. (2017). Social Dimension and Participation in Vocational Education and Training. Proceedings of the 2nd conference Crossing Boundaries in VET. University of Rostock, Institute for Vocational Education (ibp). Online: https://www.researchgate.net/publication/320083654_Social_Dimensions_and_ Participation_in_Vocational_Education_Proceedings_of_the_2nd_Crossing_boundaries_in_ VET_Conference_Rostock_2017

Wilkens, I., \& Leber, U. (2003). Partizipation an beruflicher WeiterbildungEmpirische Ergebnisse auf Basis des Sozio-Ökonomischen Panels. Mitteilungen aus der Arbeitsmarkt- und Berufsforschung, 36(3), 329-337.

Brater, M. (2010). Beruf und Bildung: Berufliche Bildung. In F. Böhle, G. Voß \& G. Wachtler (Hrsg.) Handbuch Arbeitssoziologie (S. 805-837). Wiesbaden: VS Verlag für Sozialwissenschaften.

\section{Bibliographical Notes}

Prof. Franz Kaiser is a full professor and director of the Institute for Vocational Education at the University of Rostock, Germany. His lectures and research focus on occupational research, curricula and training regulations development, group dynamics, VET teachers, international research in VET, time concepts and the critical theory of Bildung.

Susann Krugmann, M.Sc., research assistant at the Institute for Vocational Education at the University of Rostock; research and work focus: Specialist counselling for Bachelor's and Master's degree courses, structures of vocational school teacher training, vocational and study orientation. 